\title{
Impact of Body Position on Lung Deposition of Nebulized Surfactant in Newborn Piglets on Nasal Continuous Positive Airway Pressure
}

\author{
Doris Cunha-Goncalves ${ }^{a, c}$ Anders Nord ${ }^{b, c}$ Federico Bianco ${ }^{d}$ \\ Fabrizio Salomone ${ }^{d}$ Francesca Ricci $^{d}$ Martin Schlun ${ }^{e}$ Rikard Linner ${ }^{a, c}$ \\ Valeria Perez-de-Sab, \\ aDepartment of Cardiothoracic Anesthesia and Intensive Care, Skåne University Hospital, Lund, Sweden; \\ ${ }^{b}$ Department of Pediatric Anesthesia and Intensive Care, Skåne University Hospital, Lund, Sweden; ${ }^{\circ}$ Department \\ of Clinical Sciences, Lund University, Lund, Sweden; ${ }^{\mathrm{d}}$ Department of Preclinical Pharmacology, R\&D, Chiesi

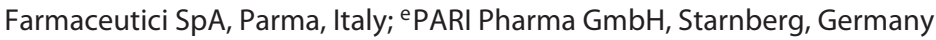

\section{Keywords}

Noninvasive ventilation $\cdot$ Prone position · Radionuclide imaging $\cdot$ Surfactant $\cdot$ Aerosols

\begin{abstract}
Introduction: The ideal body position during surfactant nebulization is not known. Objective: The aim of this study was to determine whether body positioning during surfactant nebulization influences surfactant distribution and deposition in the lungs. Methods: Twenty-four 12- to 36-h-old fullterm piglets $(1.3-2.2 \mathrm{~kg})$ on nasal continuous positive airway pressure (nCPAP) were randomized into four groups: lateral decubitus with right or left side up, prone or supine positions ( $n=6$ each). All animals received $200 \mathrm{mg} \mathrm{kg}^{-1}$ of poractant alfa mixed with $200 \mathrm{MBq}$ of ${ }^{99 \mathrm{~m}_{\text {technetium-nanocolloid via }}}$ a customized eflow-Neos investigational vibrating-membrane nebulizer. Surfactant deposition (percentage of the administered dose) was measured by gamma scintigraphy. Results: Comparing all groups, the mean total lung surfactant deposition was significantly higher in the prone position $(32.4 \pm 7.7 \%, p=0.03)$. The deposition in this group was higher in the right lung $(21.0 \pm 8.6$ vs. $11.3 \pm 5.7 \%, p=0.04)$. When nebulization was performed in the lateral decubitus,
\end{abstract}

most of the surfactant was found in the dependent lung, regardless of which side the piglet lay on (right side up $15.3 \pm$ 1.0 vs. $3.4 \pm 1.0 \%, p=0.06$, and left side up $11.2 \pm 9.8$ vs. 1.8 $\pm 0.7 \%, p=0.04)$. Conclusions: In spontaneously breathing animals on nCPAP, the prone position yielded the highest lung dose. Higher deposition rates in the dependent lung while on lateral decubitus indicates that deposition was also influenced by gravity.

(c) 2020 The Author(s)

Published by S. Karger AG, Basel

\section{Introduction}

Prematurely born infants have structurally immature lungs that are surfactant deficient, and they are prone to developing respiratory distress syndrome (RDS) [1]. Since 2013, expert societies worldwide have recommended initial ventilatory support with continuous positive airway pressure (CPAP) for infants at risk of RDS at birth $[2,3]$.

Nasal CPAP (nCPAP) reduces the need for invasive mechanical ventilation [4], but rescue surfactant replacement therapy still plays a crucial role in the treatment of RDS in very premature infants. These infants have a pre- karger@karger.com www.karger.com/neo

Karger $\stackrel{\text { ' }}{5}$

BOPEN ACCESS
(C) 2020 The Author(s)

Published by S. Karger AG, Basel

This is an Open Access article licensed under the Creative Commons Attribution-NonCommercial-4.0 International License (CC BY-NC) (http://www.karger.com/Services/OpenAccessLicense), applicable to the online version of the article only. Usage and distribution for commercial purposes requires written permission.
Doris Cunha-Goncalves

Thorax (Plan 8)

Skåne University Hospital, SUS Lund

SE-221 85 Lund (Sweden)

doris.cunha_goncalves@med.lu.se 
sumed small surfactant pool [1], and nCPAP alone fails in $43 \%$ of cases [5]. Mechanical ventilation causes further lung injury during RDS, and the incidence of bronchopulmonary dysplasia remains high [3].

Less and minimally invasive techniques for surfactant instillation have decreased adverse outcomes [6]. Nevertheless, laryngoscopy by skilled personnel is needed, which is potentially harmful, and mechanical ventilation cannot always be avoided.

Early attempts at surfactant nebulization yielded low lung deposition [7], and no beneficial effects were observed in a clinical trial with a jet nebulizer [8]. However, nebulizer efficiency has improved considerably [9], and a feasibility study with the customized eFlow-Neos investigational vibrating-membrane nebulizer system (PARI Pharma $\mathrm{GmbH}$, Gräfelfing, Germany) showed a lung deposition of $14 \%$ of the administered dose of poractant alfa in neonatal piglets on nCPAP [10]. A small randomized controlled clinical trial with the same nebulizer system demonstrated that surfactant nebulization in preterm infants on nCPAP might reduce the need for intubation in the first $72 \mathrm{~h}$ of life in infants born at $32^{0}-33^{6}$ weeks' gestation [11].

Several factors, such as breathing pattern and inspiratory flow rate [12], affect the lung deposition of nebulized drugs, but even body position may influence deposition as changes in posture modify transpulmonary pressure gradients, regional ventilation heterogeneity, and segmental lung aeration $[13,14]$. To optimize the nebulization time and deposition rates, it is essential not only to improve nebulizer performance but also to define other additional strategies that might improve lung delivery of surfactant.

There is insufficient data on the optimal body position during surfactant nebulization [15]. We hypothesized that body positioning would influence lung deposition of aerosolized surfactant. Newborn piglets on nCPAP, lying in different positions, received a mixture of poractant alfa and ${ }^{99 m}$ technetium-nanocolloid via nebulization. The lung dose of the surfactant was assessed by gamma scintigraphy.

\section{Materials and Methods}

Twenty-four 12- to 36-h-old full-term newborn piglets weighing 1.3-2.2 $\mathrm{kg}$ were randomized into 4 groups: prone position (prone), supine position (supine), lateral decubitus with the right side up (right-up), or the left side up (left-up), with $n=6$ per group. The combined data from the 12 piglets in the lateral decubitus were part of a nebulization study on the effect of different noninvasive ventilation modes on lung deposition of surfactant [16].

\section{Preparation and Anesthesia}

Anesthesia and sedation, as well as details on the nasal prongs and the respiratory circuit, are presented online as supplementary material (see www.karger.com/doi/10.1159/000508349 for all online suppl. material). An ear vein and a femoral artery were catheterized, and the piglets were placed in an incubator with a $30^{\circ}$ head elevation. The CPAP source was a Servo-i ventilator (Maquet, Solna, Sweden), set on nCPAP mode with an inspired oxygen fraction $\left(\mathrm{FiO}_{2}\right)$ of 0.4 and CPAP of $3 \mathrm{~cm} \mathrm{H}_{2} \mathrm{O}$.

The mean arterial pressure (MAP), heart rate (HR; via a 3-lead ECG), regional cerebral oximetry ( $\mathrm{rSO}_{2}$ near-infrared spectroscopy, INVOS 5100C, Somanetics Corporation, Troy, MI USA), and rectal temperature were continuously monitored.

\section{Experimental Protocol}

Just before nebulization, $200 \mathrm{mg} \mathrm{kg}^{-1}$ of poractant alfa $(2.5 \mathrm{~mL}$ $\mathrm{kg}^{-1}$ of Curosurf ${ }^{\circledR} 80 \mathrm{mg} \mathrm{mL}^{-1}$; Chiesi Farmaceutici, Parma, Italy), was mixed with $200 \mathrm{MBq}^{99 \mathrm{~m}}$ Tc-nanocolloid (Nanocoll ${ }^{\circledR}$, GE Healthcare AB, Stockholm, Sweden). The particle size of the poractant alfa droplets delivered by the eFlow-Neos investigational vibratingmembrane nebulizer was $3.0 \pm 0.1 \mu \mathrm{m}$ in mass median aerodynamic diameter, with a geometric standard deviation of 1.5 [17].

With the piglets lying in the randomized position, lidocaine gel $2 \%$ was applied to the nostrils, the prongs were inserted, and the nCPAP started. Ten minutes later, continuous unsynchronized surfactant nebulization was begun. The respiratory rate, tidal volume, and air leak were recorded every $5 \mathrm{~min}$. Arterial blood was collected just before and $15 \mathrm{~min}$ after the start of nebulization, and $10 \mathrm{~min}$ after the end of nebulization. Blood was analyzed in an ABL 90 FLEX blood gas analyzer (Radiometer, Copenhagen, Denmark).

After surfactant administration, lung deposition was assessed in a gamma camera (Philips Skylight, Philips AB, Stockholm, Sweden) as described in the online supplementary material. We report depositions in the nasopharynx, trachea, each lung, and in the stomach. Afterwards, the animals were killed with a lethal i.v. dose of fentanyl, thiopental, and potassium chloride.

\section{Statistical Analysis}

Statistical analysis was performed with SigmaPlot 14 (Systat Software Inc., San Jose, CA, USA). One-way ANOVA was used to assess the overall differences in treatment among all groups. The Student-Newman-Keuls test was used as a post hoc test for stepwise multiple comparisons. RM-ANOVA with the post hoc Bonferroni test was used to evaluate within-group changes from baseline in blood gases and oxygenation during nebulization. Differences in side deposition and ventilatory/nebulizer parameters between two specific groups (i.e., prone vs. supine, and right-up vs. left-up) were assessed by the $t$ test. Whenever required, the corresponding nonparametric tests were used. $p$ values $<0.05$ were considered significant, and results are shown as the mean \pm SD and 95\% CI (max., min.), if not otherwise stated.

\section{Results}

The bodyweights were $1.66 \pm 0.22 \mathrm{~kg}(1.42,1.89)$ in the prone, $1.72 \pm 0.31 \mathrm{~kg}(1.40,2.04)$ in the supine, $1.63 \pm 0.17$ $\mathrm{kg}(1.45,1.81)$ in the right-up, and $1.63 \pm 0.19 \mathrm{~kg}(1.43$, 

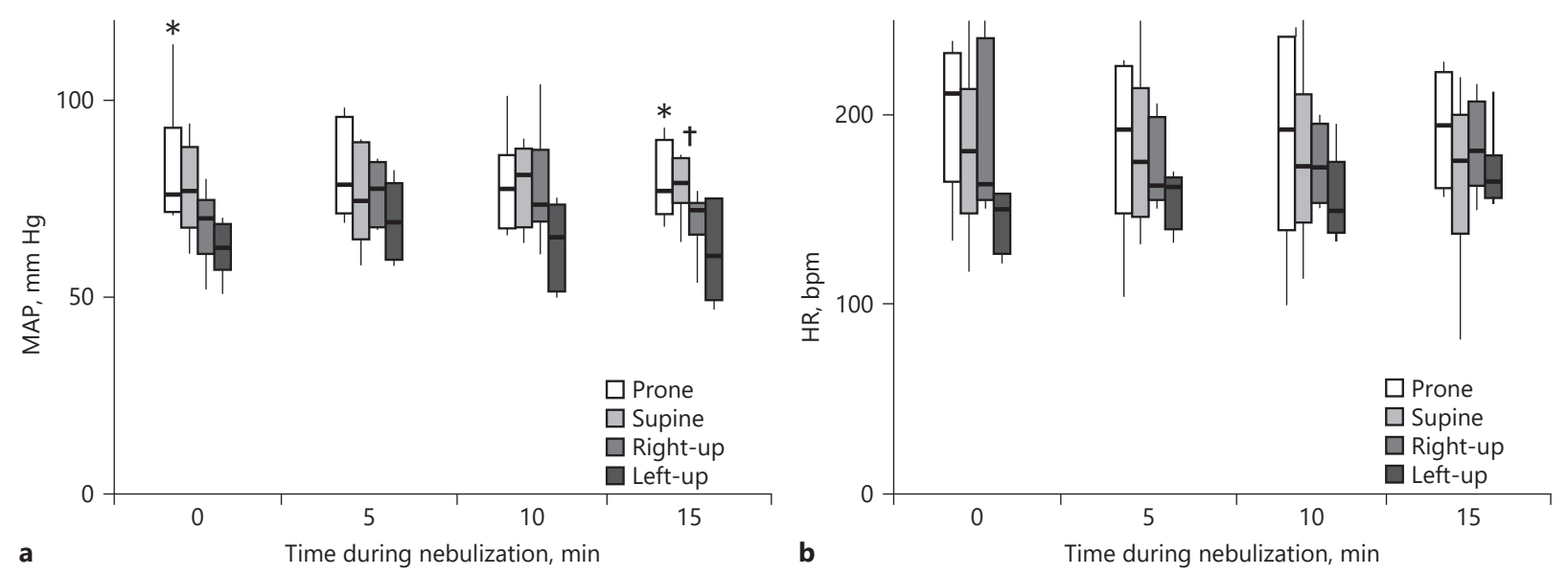

Fig. 1. a, b MAP and HR during nebulization. Box plots and whiskers depict the median, 5th and 95th percentiles for each group at 5 -min intervals during nebulization. ${ }^{*} p<0.05$ between prone versus left-up (ANOVA); ${ }^{\dagger} p<$ 0.05 supine versus left-up (ANOVA) at the respective time points. There were no significant changes within groups between the different stages.

Table 1. Cerebral oximetry and arterial blood gases under nebulization

\begin{tabular}{|c|c|c|c|c|c|}
\hline & $\begin{array}{l}\text { Prone } \\
(n=6)\end{array}$ & $\begin{array}{l}\text { Supine } \\
(n=6)\end{array}$ & $\begin{array}{l}\text { Right-up } \\
(n=6)\end{array}$ & $\begin{array}{l}\text { Left-up } \\
(n=6)\end{array}$ & $\begin{array}{l}\text { ANOVA- } \\
\text { All }\end{array}$ \\
\hline $\mathrm{rSO}_{2}, \%$ & $62 \pm 5(56,68)$ & $61 \pm 5(56,67)$ & $61 \pm 5(56,66)$ & $63 \pm 6(56,70)$ & 0.94 \\
\hline \multicolumn{6}{|l|}{$\mathrm{SaO}_{2}, \%$} \\
\hline $0 \mathrm{~min}$ & $99 \pm 1(98,100)$ & $100 \pm 0(100,100)$ & $98 \pm 4(94,100)$ & $97 \pm 7(90,100)$ & 0.30 \\
\hline $15 \mathrm{~min}$ & $95 \pm 9(87,100)$ & $96 \pm 5(91,100)$ & $94 \pm 10(84,100)$ & $97 \pm 2(95,99)$ & 0.61 \\
\hline End & $97 \pm 5(92,100)$ & $97 \pm 4(94,100)$ & $96 \pm 6(90,100)$ & $99 \pm 2(97,100)$ & 0.45 \\
\hline RM-ANOVA & 0.23 & 0.09 & 0.57 & 0.78 & \\
\hline \multicolumn{6}{|l|}{$\mathrm{PaO}_{2}, \mathrm{kPa}$} \\
\hline $0 \mathrm{~min}$ & $20.7 \pm 5.1(15.3,26.0)$ & $17.9 \pm 2.9(15.0,21.0)$ & $17.0 \pm 5.8(11.0,23.1)$ & $19.1 \pm 6.9(11.8,26.4)$ & 0.68 \\
\hline $15 \mathrm{~min}$ & $12.2 \pm 3.2(8.8,15.6)$ & $11.3 \pm 4.9(6.2,16.5)$ & $12.5 \pm 5.2(7.0,18.0)$ & $13.5 \pm 4.8(8.5,18.6)$ & 0.6 \\
\hline End & $12.4 \pm 3.0(9.2,15.6)$ & $10.9 \pm 4.5(6.2,15.6)$ & $13.1 \pm 5.7(7.0,19.1)$ & $15.8 \pm 5.0(10.5,21.0)$ & 0.37 \\
\hline RM-ANOVA & $<0.001$ & 0.14 & 0.43 & 0.11 & \\
\hline \multicolumn{6}{|l|}{$\mathrm{PaCO}_{2}, \mathrm{kPa}$} \\
\hline $0 \mathrm{~min}$ & $6.8 \pm 1.1(5.7,8.0)$ & $6.2 \pm 0.5(5.7,6.8)$ & $6.2 \pm 1.2(4.9,7.4)$ & $7.2 \pm 1.3(5.9,8.5)$ & 0.88 \\
\hline $15 \min$ & $7.5 \pm 1.1(6.4,8.7)$ & $7.1 \pm 0.8(6.2,7.9)$ & $7.1 \pm 1.4(5.7,8.6)$ & $8.1 \pm 2.0(6.0,10.2)$ & 0.92 \\
\hline End & $7.1 \pm 1.0(6.0,8.1)$ & $6.5 \pm 0.7(5.7,7.2)$ & $6.6 \pm 0.7(5.9,7.4)$ & $7.2 \pm 1.1(6.0,8.4)$ & 0.88 \\
\hline RM-ANOVA & 0.01 & 0.09 & 0.15 & 0.25 & \\
\hline
\end{tabular}

Data are presented as the mean \pm SD and 95\% CI (min., max.). RM-ANOVA denotes repeated-measures ANOVA for within-group comparison versus $0 \mathrm{~min}$, while ANOVA-All describes the comparison between all groups for each stage. 0 min, 15 min, and End (10 min after nebulization) are the time points during treatment.

1.83 ) in the left-up groups $(p=0.891)$. There were no differences between groups for blood gases, respiratory rate, cerebral oximetry, and hemodynamics before the start of nCPAP (data not shown). With the animals on nCPAP, at the start of nebulization (0 min), MAP (Fig. 1a) was slightly higher in the prone compared to the left-up position. After $15 \mathrm{~min}$, both the prone and supine groups had higher MAP than the left-up group. However, during nebulization, blood pressure and HR (Fig. 1a, b) remained stable in all groups, with no within-group changes. At all 
Fig. 2. Scintigraphy images in the anterior projection from a single subject in each group. Typical examples of gamma camera images showing deposition from an individual in each group. These anterior planar images were obtained after nebulization and delineation of the lungs by the i.v. injection of ${ }^{99 \mathrm{~m}} \mathrm{Tc}$-macro aggregated albumin, which was trapped in the lung capillaries. R, right side; L, left side.

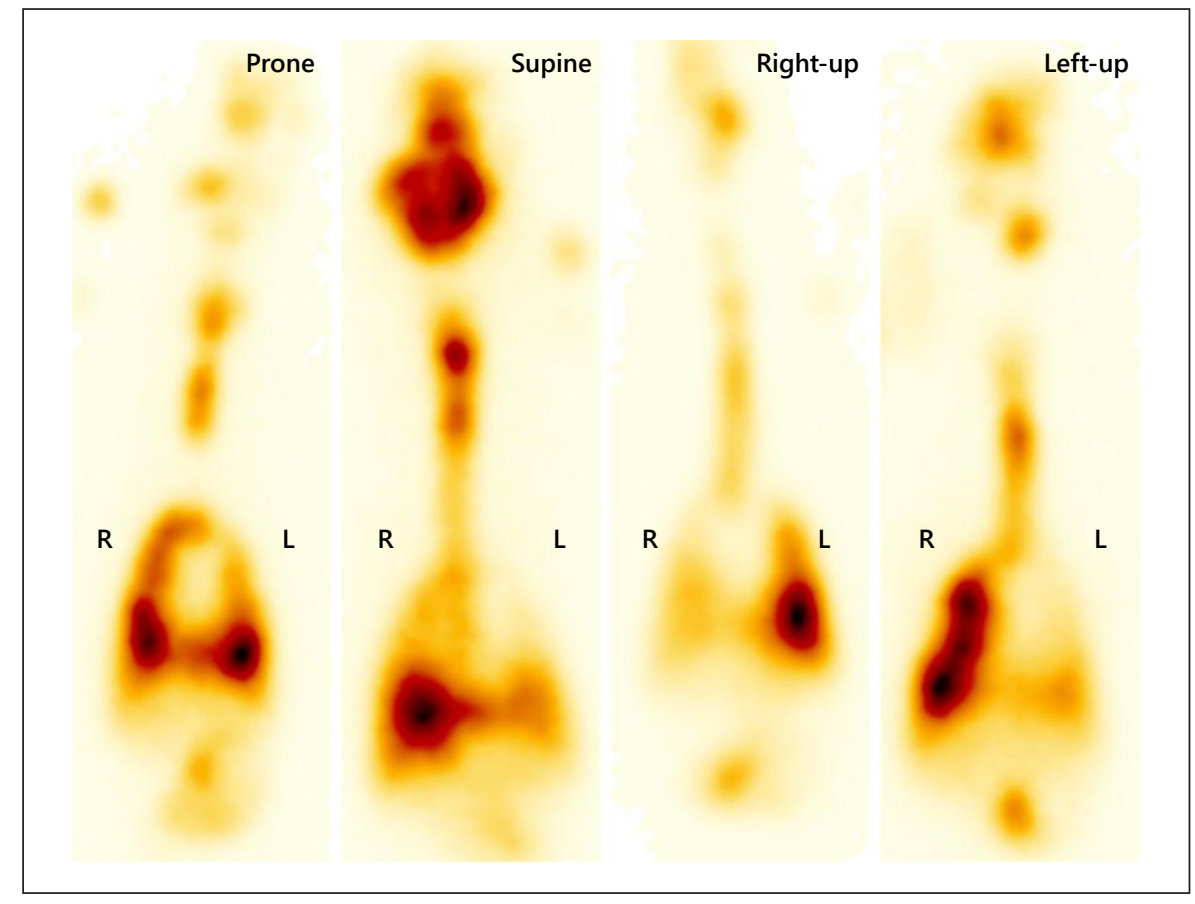

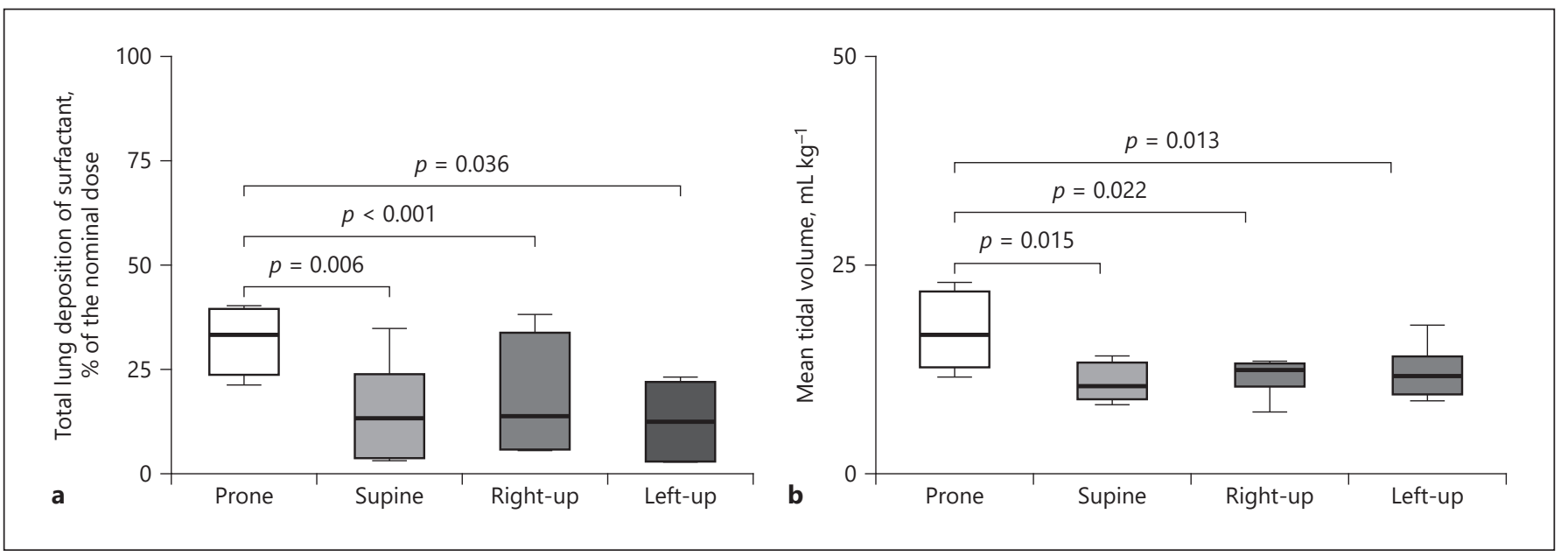

Fig. 3. Total lung deposition of surfactant (\% of the nominal dose) and mean indexed tidal volume during nebulization. a Box plots and whiskers depict the median, 5th and 95th percentiles for deposition in each group. The prone group was significantly different from the other three groups; $p$ values are shown. b Box plots and

times, $\mathrm{SaO}_{2}$ (arterial oxygen saturation) and $\mathrm{rSO}_{2}$ remained stable in all groups (Table 1). Despite no betweengroup differences, $\mathrm{PaO}_{2}$ (arterial partial pressure of oxygen) decreased and $\mathrm{PaCO}_{2}$ (arterial partial pressure of carbon dioxide) increased in the prone group by the end of nebulization (Table 1). whiskers depict the median, 5th and 95th percentiles for the mean indexed tidal volumes for each group during the whole nebulization period. Tidal volume indexed to body weight was significantly higher in the prone group; $p$ values are shown.

Figure 2 shows typical deposition images from 1 animal in each group. Overall, the lung deposition of surfactant was highest in the prone position (Fig. 3a). In this position, the deposition was greater in the right lung (Table 2). In the lateral positions, most of the surfactant was found in the dependent lung (Table 2), but deposition in 
Table 2. Surfactant deposition

\begin{tabular}{|c|c|c|c|c|}
\hline & $\begin{array}{l}\text { Prone } \\
(n=6)\end{array}$ & $\begin{array}{l}\text { Supine } \\
(n=6)\end{array}$ & $\begin{array}{l}\text { Right-up } \\
(n=6)\end{array}$ & $\begin{array}{l}\text { Left-up } \\
(n=6)\end{array}$ \\
\hline Right lung & $21.0 \pm 8.6(12.0,30.1)$ & $10.7 \pm 11.4(0.0,22.7)$ & $3.4 \pm 1.0(2.4,4.4)$ & $11.2 \pm 9.8(0.9,21.5)$ \\
\hline$p$ value $(t$ test $)$ & 0.04 & 0.22 & 0.06 & 0.04 \\
\hline Nasopharynx & $12.2 \pm 1.6(10.5,13.9)$ & $28.0 \pm 8.4(19.2,36.9)$ & $15.8 \pm 8.5(6.9,24.8)$ & $16.4 \pm 4.5(11.6,21.1)$ \\
\hline $\begin{array}{l}\text { Trachea } \\
p \text { value (ANOVA) }\end{array}$ & \multicolumn{4}{|c|}{0.384} \\
\hline $\begin{array}{l}\text { Stomach } \\
p \text { value (ANOVA) }\end{array}$ & \multicolumn{4}{|c|}{0.034} \\
\hline
\end{tabular}

Data are the $\%$ of the administered dose found in the animals, presented as the mean \pm SD and 95\% CI (min., max.). ANOVA denotes differences among all groups; the $t$ test (paired) denotes differences between the right and left lungs within each group.

Table 3. Ventilatory parameters under nebulization, nebulizing time, and nebulizer output

\begin{tabular}{lllllll}
\hline & $\begin{array}{l}\text { Prone } \\
(n=6)\end{array}$ & $\begin{array}{l}\text { Supine } \\
(n=6)\end{array}$ & $\begin{array}{l}p \\
\text { value }\end{array}$ & $\begin{array}{l}\text { Right-up } \\
(n=6)\end{array}$ & $\begin{array}{l}\text { Left-up } \\
(n=6)\end{array}$ & $\begin{array}{l}p \\
\text { value }\end{array}$ \\
\hline value
\end{tabular}

Data presented as the mean \pm SD and $95 \%$ CI (min., max.). Minute volume, respiratory rate, and leakage (as measured by the Servo-i ventilator and displayed in the user interface) are the mean values during the whole nebulization time. We compared prone versus supine and right-up versus left-up ( $t$ test), and all groups (ANOVA).

the nondependent right lung was greater than in the nondependent left lung $(3.4 \pm 1.0$ vs. $1.8 \pm 0.7 \%, p=0.01$; Table 2). A variable amount of surfactant was found in the nasopharynx, trachea, and stomach of all animals (Table 2).

The mean tidal volume throughout nebulization was highest in the prone group, but similar in the other three groups (Fig. 3b). Overall, the left-up group had the lowest minute ventilation and respiratory rates (Table 3 ), but the respiratory rate was otherwise comparable among the three other groups (Table 3).

It took between 16 and $19 \mathrm{~min}$ to nebulize $2.5 \mathrm{~mL}$ $\mathrm{kg}^{-1}$ of poractant alfa (Table 3 ). There was no visually detectable residual volume in the nebulizer at the end of nebulization, and the remaining radioactivity in the nebulizer and prongs was usually less than $1 \%$ of the nebulized dose. Although air leakage in the circuit was

Impact of Body Position on Lung Dose of Aerosolized Surfactant comparable in all groups, it varied from $1.7 \pm 1.3 \%$ in the prone group to $8.5 \pm 11.6 \%$ in the left-up group (Table 3).

\section{Discussion}

Our study is the first comparing lung deposition of nebulized surfactant with an entirely noninvasive interface in neonatal piglets lying in different body positions during nebulization. The highest lung dose of the surfactant was achieved in the prone position. The deposition was influenced by gravity, with higher values being found in the dependent lungs while on the lateral decubitus positions.

Aerosol therapy in neonates is very challenging due to the small radius of their airways and their rapid and shal- 
low breathing [12]. Despite being a critical factor determining clinical efficiency, data on the deposition and distribution of nebulized drugs in neonates is limited. Lung deposition of aerosolized aqueous solutions with standard nebulizers in newborns is estimated as less than 3\% of the nominal dose [18]. In contrast, salbutamol deposition with two investigational eFlow-Neos nebulizers in an in vitro neonatal lung model was $18-21 \%$ of the nominal dose [9]. The mean lung deposition of poractant alfa in the different groups in our study ranged from 13 to $32 \%$, i.e., $26-64 \mathrm{mg} \mathrm{kg}^{-1}$ of phospholipids. To our knowledge, there are no previous reports of such a significant in vivo lung deposition of nebulized surfactant in a neonatal model with an entirely noninvasive interface. Apart from our earlier study in the lateral decubitus showing $14 \%$ deposition with the same eFlow-Neos investigational nebulizer [10], and two quasi-noninvasive atomization studies with a rigid supraglottic cannula with deposition of $32 \%$ of the nominal dose in preterm lambs [19] and $40 \%$ in neonatal piglets [20], the best result ever obtained by a noninvasive technique was a lung deposition of less than $1 \%$ of the administered surfactant in preterm lambs [7], which took $3 \mathrm{~h}$. Comparably, in our study, although poractant alfa has the highest phospholipid content of all available exogenous surfactants, nebulization of $2.5 \mathrm{~mL}$ $\mathrm{kg}^{-1}$ of the undiluted drug took between 16 and $19 \mathrm{~min}$, which gives a mean output range of $0.22-0.27 \mathrm{~mL} \mathrm{~min}^{-1}$, close to the average output for aqueous solutions with standard nebulizers [18].

The highest and most reproducible deposition values were found in the prone-positioned animals, which also had the largest tidal volumes. Compared to the supine position, ventilation heterogeneity decreases in the prone position [13], which can improve ventilation and might reduce the variability of aerosol delivery. We found no other noninvasive surfactant nebulization study conducted in this position, but thoracic-abdominal synchrony improves and tidal volume increases in prone-positioned premature infants [21], facts that might facilitate aerosol delivery to the lungs [12]. A significant amount of surfactant was found in the nasopharynx, particularly in the supine-positioned animals, and, with continued CPAP, some of this surfactant might eventually reach the lungs.

Lung distribution of both instilled and nebulized surfactant is dependent on gravity [10,22]. We once again confirmed that surfactant nebulized in the lateral position deposits preferentially in the lower lung.

In the prone and supine positions, aerosol deposition in the larger right lung was twice that in the left lung. For the upper lung in the lateral decubitus, the deposition was higher in the right-up than the left-up position (3.4 vs. $1.8 \%, p=0.01$ ), probably because - due to the complexity of lung architecture - ventilation is not only gravity dependent [23]. In the right-up position, the smaller left lung loses volume due to compression by the heart and abdomen. This volume loss outweighs the physiological gravity-dependent increase in ventilation that would favor the left dependent lung, and ventilation becomes relatively greater in the nondependent right lung [24].

Cerebral oxygen saturation remained stable, and there were only minor changes in blood gases during nebulization. The mean $\mathrm{PaCO}_{2}$ increased $0.3 \mathrm{kPa}$ in the prone group, probably reflecting fluid accumulation in these healthy lungs, as this group had the highest surfactant deposition in the airways. The same mechanism may have accounted for the fall in $\mathrm{PaO}_{2}$. It is possible that, with CPAP adjustments and longer observation times, blood gases would have improved. In surfactant-depleted piglets, Rey-Santano et al. [25] observed a dose-response curve for improvements in lung injury scores and oxygenation indices with increasing doses of nebulized surfactant (dose range $200-400 \mathrm{mg} \mathrm{kg}^{-1}$ ). However, higher doses showed delayed recovery of oxygenation and shunt parameters.

There are several limitations to our study. It was a short-term study with small groups of healthy mature newborn piglets, and these results cannot be directly translated to premature neonates. The piglets were sedated during the treatment, which might have improved ventilation during nebulization, as there was no struggling, but may also have predisposed to atelectasis, decreased respiratory drive, and increased airway resistance. Furthermore, there was high intragroup variability in the deposition, but this is a known problem with nebulization in infants. Finally, piglets lie naturally prone, and whether this position would have a similar impact on surfactant deposition in infants requires further study.

In conclusion, the lung dose of poractant alfa obtained with the eFlow-Neos investigational nebulizer in newborn piglets on nCPAP ranged from 13 to $32 \%$ of the nominal dose, depending on the animal's posture during nebulization. Despite a significant overall intragroup variability, the deposition was highest and most reproducible in the prone position. Deposition in the lateral decubitus was influenced by gravity. Nebulization was fast, and there were no signs of hemodynamic instability. These experimental findings in healthy piglets suggest that body position influences the lung dose of the surfactant achieved by nebulization during nCPAP, which needs to be confirmed in an RDS animal model. 


\section{Statement of Ethics}

The committee on animal welfare research ethics at Lund University approved the study. The animals received care according to the European guidelines for the protection of animals used for scientific purposes (directive 2010/63/EU).

\section{Disclosure Statement}

Federico Bianco, Fabrizio Salomone, and Francesca Ricci are Chiesi Farmaceutici SpA employees, and Martin Schlun is a PARI Pharma employee.

\section{Funding Sources}

The study was performed at Lund University facilities and was partly funded by Chiesi Farmaceutici SpA (Parma, Italy), who supplied the poractant alfa for free and covered the expenses for the disposables and the salaries of the laboratory personnel. The eFlow-Neos nebulizers were provided for free by PARI Pharma GmbH (Munich, Germany).

\section{Author Contributions}

We confirm that all authors significantly contributed to the design, acquisition of data, data analysis, and drafting of the final content of the manuscript.

\section{References}

1 Jobe AH. Mechanisms to explain surfactant responses. Biol Neonate. 2006;89(4):298-302.

2 Committee on Fetus and Newborn; American Academy of Pediatrics. Respiratory support in preterm infants at birth. Pediatrics. 2014 Jan;133(1):171-4.

3 Sweet DG, Carnielli V, Greisen G, Hallman M, Ozek E, Te Pas A, et al. European consensus guidelines on the management of respiratory distress syndrome - 2019 Update. Neonatology. 2019;115(4):432-50.

4 Subramaniam P, Ho JJ, Davis PG. Prophylactic nasal continuous positive airway pressure for preventing morbidity and mortality in very preterm infants. Cochrane Database Syst Rev. 2016 Jun;6:CD001243.

5 Fuchs H, Lindner W, Leiprecht A, Mendler MR, Hummler HD. Predictors of early nasal CPAP failure and effects of various intubation criteria on the rate of mechanical ventilation in preterm infants of $[\{\mathrm{LT}\}] 29$ weeks gestational age. Arch Dis Child Fetal Neonatal Ed. 2011 Sep;96(5):F343-7.

6 Rigo V, Lefebvre C, Broux I. Surfactant instillation in spontaneously breathing preterm infants: a systematic review and meta-analysis. Eur J Pediatr. 2016 Dec;175(12):1933-42.

7 Rahmel DK, Pohlmann G, Iwatschenko P, Volland J, Liebisch S, Kock H, et al. The nonintubated, spontaneously breathing, continuous positive airway pressure (CPAP) ventilated pre-term lamb: a unique animal model. Reprod Toxicol. 2012 Sep;34(2):204-15.

8 Berggren E, Liljedahl M, Winbladh B, Andreasson B, Curstedt T, Robertson B, et al. Pilot study of nebulized surfactant therapy for neonatal respiratory distress syndrome. Acta Paediatr. 2000 Apr;89(4):460-4.

9 Tiemersma S, Minocchieri S, van Lingen RA, Nelle M, Devadason SG. Vibrating membrane devices deliver aerosols more efficient than standard devices: a study in a neonatal upper airway model. J Aerosol Med Pulm Drug Deliv. 2013 Oct;26(5):280-6.
10 Linner R, Perez-de-Sa V, Cunha-Goncalves D. Lung deposition of nebulized surfactant in newborn piglets. Neonatology. 2015;107(4): 277-82.

11 Minocchieri S, Berry CA, Pillow JJ. CureNeb Study Team. Nebulised surfactant to reduce severity of respiratory distress: a blinded, parallel, randomised controlled trial. Arch Dis Child Fetal Neonatal Ed. 2019;104(3):F313-9.

12 Cole $\mathrm{CH}$. Special problems in aerosol delivery: neonatal and pediatric considerations. Respir Care. 2000 Jun;45(6):646-51.

13 Richter T, Bellani G, Scott Harris R, Vidal Melo MF, Winkler T, Venegas JG, et al. Effect of prone position on regional shunt, aeration, and perfusion in experimental acute lung injury. Am J Respir Crit Care Med. 2005 Aug; 172(4):480-7.

14 Lupton-Smith A, Argent A, Rimensberger P, Frerichs I, Morrow B. Prone positioning improves ventilation homogeneity in children with acute respiratory distress syndrome. Pediatr Crit Care Med. 2017 May;18(5):e22934.

15 Polin RA, Carlo WA; Committee on Fetus and Newborn; American Academy of Pediatrics. Surfactant replacement therapy for preterm and term neonates with respiratory distress. Pediatrics. 2014 Jan;133(1):156-63.

16 Nord A, Linner R, Salomone F, Bianco F, Ricci F, Murgia X, et al. Lung deposition of nebulized surfactant in newborn piglets: nasal CPAP vs Nasal IPPV. Pediatr Pulmonol. 2020 Feb;55(2):514-20.

17 Bianco F, Ricci F, Catozzi C, Murgia X, Schlun $\mathrm{M}$, Bucholski A, et al. From bench to bedside: in vitro and in vivo evaluation of a neonatefocused nebulized surfactant delivery strategy. Respir Res. 2019 Jul;20(1):134.
18 Darquenne C. The ISAM textbook of aerosol medicine [Internet]. Rochelle: Mary Ann Libert Publishing; 2015.

19 Milesi I, Tingay DG, Lavizzari A, Bianco F, Zannin E, Tagliabue P, et al. Supraglottic atomization of surfactant in spontaneously breathing lambs receiving continuous positive airway pressure. Pediatr Crit Care Med. 2017 Sep;18(9):e428-34.

20 Nord A, Linner R, Milesi I, Zannin E, di Castri M, Bianco F, et al. A novel delivery system for supraglottic atomization allows increased lung deposition rates of pulmonary surfactant in newborn piglets. Pediatr Res. 2020;87(6): 1019-24.

21 Gouna G, Rakza T, Kuissi E, Pennaforte T, Mur S, Storme L. Positioning effects on lung function and breathing pattern in premature newborns. J Pediatr. 2013 Jun;162(6):1133-7. e1.

22 Broadbent R, Fok TF, Dolovich M, Watts J, Coates G, Bowen B, et al. Chest position and pulmonary deposition of surfactant in surfactant depleted rabbits. Arch Dis Child Fetal Neonatal Ed. 1995 Mar;72(2):F84-9.

23 Galvin I, Drummond GB, Nirmalan M. Distribution of blood flow and ventilation in the lung: gravity is not the only factor. $\mathrm{Br} \mathrm{J} \mathrm{An-}$ aesth. 2007 Apr;98(4):420-8.

24 Chang H, Lai-Fook SJ, Domino KB, Schimmel C, Hildebrandt J, Robertson HT, et al. Spatial distribution of ventilation and perfusion in anesthetized dogs in lateral postures. J Appl Physiol. 2002 Feb;92(2):745-62.

25 Rey-Santano C, Mielgo VE, Gomez-Solaetxe MA, Bianco F, Salomone F, Loureiro B. Nebulized poractant alfa reduces the risk of respiratory failure at 72 hours in spontaneously breathing surfactant-deficient newborn piglets. Crit Care Med. 2020;48(6):e523-31. 